\title{
Seasonal and Diurnal Variability of Rain Heights at an Equatorial Station
}

\author{
Yussuff Abayomi Isiaka O*, Nor Hisham Haji Khamis** \\ *Department of Electronic and Computer Engineering, Lagos State University, Nigeria \\ ** Department of Communications Engineering, Universiti Teknologi Malaysia, Malaysia
}

\begin{abstract}
Seasonal and diurnal rain heights variation at Universiti Teknologi Malaysia, Johor was studied.Slant path rain attenuation prediction and modeling is crucial to satellite equipment design; a major input is the rain height. One year meteorological ground-based, S-band, 3D RAPIC precipitation radar data at $500 \mathrm{~m}$ resolution sourced from the Malaysian Meteorological Department was complemented with two-year TRMM PR data sourced from JAXA Earth Observation Research Center. After filtering, sorting, extraction and decoding of the data, vertical reflectivity profiles were constructed; from which rain height parameters were extracted. TRMM PR processed monthly (3A25) and daily (2A23) rainfall precipitation data were similarly used to obtain rain height parameters to investigate the seasonal and diurnal variations. Results from this work suggested that rain height parameters are influenced by both seasonal and diurnal variations. Higher seasonal variability was observed during south-west and pre-southwest monsoons. Rain heights werealso observed to be higher in the night than in the day time.
\end{abstract}

Copyright (C) 2015 Institute of Advanced Engineering and Science. All rights reserved.

\section{Corresponding Author:}

Abayomi Isiaka O. Yussuff,

Department of Electronic and Computer Engineering,

Lagos State University,

Epe campus, Lagos, Nigeria

Email: ayussuff@yahoo.com

\section{INTRODUCTION}

Rain attenuation (such as signal fading, depolarization, scattering and absorption) and noise induced by atmospheric gases, are phenomena seriously debilitating efficient and reliable earth-space signal transmissions; which are generally done above the X-band. A major factor found to be responsible rain attenuation along the slant path (aside rainfall rate, rainfall drop size, transmission frequency, elevation angle, signal polarization angle and rain/antenna temperature) [1] is the rain height.The total path attenuation is generally found by assuming constant rain up to the bottom of the melting layer (i.e.within the rain height) [2], and this subjective assumption have been found to be incorrect, particularly for tropical and equatorial stations [3]. Also, since rain height is found to be highly correlated with signal attenuation and co-channel interference due to rain drop scattering, rain height distribution is therefore important because it can be used to investigate the mechanisms responsible for variations in the attenuation distributions at any station of interest. Furthermore, rain height is location-dependent [4]. Consequently, an adequate study of rain height parameters, particularly its relationship vis-à-vis diurnal and seasonal changes, is pertinent. This will propose what time of the day or period of the year (seasonal occurrences) rain attenuation is more likely to be experienced.

Variations in seasonal and diurnal rain drop size distributions of the Asian monsoon region from disdrometer measurements have been studied by [5]. Further assessments of the of the rain impacts of the Asian monsoon on the slant path propagation, also from disdrometer measurements; sourced from Kuala 
Lumpur, Malaysia was carried out by [6]. For equatorial station like Malaysia, yearly seasonal variations are classified into two monsoon and two pre-monsoon seasons. These are pre-Southwest (April-May), Southwest (June-September), pre-Northeast (October-November) and Northeast (December-March) monsoon seasons [5]-[7].

Environmental conditions in South-west and North-east monsoon seasons from data sourced from South India, Singapore and West Sumatra have been found to be different based on observed rainfall and temperature variations; and these seasonal variations may also overlap with diurnal variation of precipitations [1]. Another factor observed to be affecting the diurnal cycle is the difference in phases of diurnal cycles for rain over ocean and over land [7]-[9]. Diurnal cycle for oceanic rain was observed by [5] to peak around midnight to early morning, while it peaked in the afternoon over land; which may lead to a less significant diurnal cycle or double-peak in rainfall for a station located along the coast line, since the rainfall characteristics would be affected both by oceanic and land rainfalls.

TRMM (Tropical Rain Measurement Mission) was a joint project between the U.S. National Aeronautics and Space Administration (NASA), and Japan National Space Development Agency of Japan (NASDA) and Communication Research Laboratory (CRL). It was launched on November 27, 1997 into a near circular orbit of approximately $350 \mathrm{Km}$ altitude with an inclination angle of 35 degrees and a period of 91.5 minutes or 15.7 orbits per day. The precipitation radar (PR) and an H-II rocket launcher that put the TRMM satellite into orbit was developed by Japan, while the U.S. provided the observatory, four other sensors (visible infrared scanner (VIRS), TRMM microwave imager (TMI), lighting imaging sensor (LIS), and cloud and earth's radiant energy system (CERES)), as well as the satellite operation systems. The satellite altitude was boosted in August 2001 to approximately $402.5 \mathrm{Km}$ with a period of 92.5 minutes (15.6 orbits per day) to extend the lifetime by reducing atmospheric drag. However, this boot in altitude introduced some sampling errors. This is because sampling errors and related biases, such as beam filling errors are reduced when altitude is low [10]. Also, since the TRMM is a non-geosynchronous remote sensing satellite, it records much fewer precipitations than actual because of its poor sampling period. For instance, a specific location in Malaysia has been observed to be orbited just about 70 times in a whole calendar year [11]. This results in inconsistent scans and serious underestimation of rain events. TRMM PR provides daily (2A23) and monthly (3A25) mean rainfall precipitation data with a resolution of $5^{\circ} \times 5^{\circ}$ latitude-longitude over the tropical regions, over both land and ocean. The non-sun-synchronous orbit makes it possible to sample virtually all local times over the course within a few weeks while at the same time reducing the diurnal bias drastically [12]. The frequency of the TRMM PR is $13.8 \mathrm{GHz}$ at an approximate wavelength of 2.2 centimeters, and with a spatial resolution of approximately $4.5 \mathrm{~km}$ (footprint). The vertical resolution is 250 metres, while its nominal sensitivity is approximately $17 \mathrm{dBZ}$ [13]. It has a surface clutter-limited swath of about $220 \mathrm{~km}$ [14], [15]. The successor to TRMM, the Global Precipitation Measurement (GPM) was launched into space in Japan on February 27, 2014 at 6:27 UTC. The GPM is an international network of satellites that provide next-generation global observations of rain and snow; and with the ability to detect stratiform precipitations with very low reflectivities.

Rain height is the boundary between the rain region and the snow region. Its boundaries correspond to the $0^{\circ} \mathrm{C}$; its detection via the bright-band $(\mathrm{BB})$ occurs during stratiform rain events [16]. Rain height $\left(H_{R}\right)$ is location-dependent and linearly related to the $0^{\circ} \mathrm{C}$ isotherm height $\left(\mathrm{H}_{0}\right)$. According to ITU-R P.839-3 [17],

$$
H_{R}=H_{0}+0.36 \mathrm{~km}
$$

Sources of prediction errors in slant path attenuation include complexity of the rainfall structure along slant-path, ambiguity in properly detecting the $\mathrm{BB}$, and the difficulties encountered in empirically relating rain and isotherm heights in the tropical and equatorial regions due to insufficient database [18]-[22]. Various applications of the rain height in several ITU-Recommendations have been well documented by [23]. Correct detection of the bright-band and estimation of the boundaries of the melting layer is crucial in quantifying the rain height parameters.Seasonal and latitudinal variations have also been reported to influence the quantification of rain height parameters [23]-[27]. Good understanding of rain height characteristics would provide valuable information about the microphysical processes involved in the precipitation (such as reflectivity and rain drop sizes and shapes); with a possibility of evolving a better approach in the estimation of rain attenuation prediction and modelling. The reflectivity factor of typical radar is given as:

$$
Z=\int_{0}^{D \max } N(D) D^{6} d D\left(\mathrm{~mm}^{6} \mathrm{~m}^{-3}\right)
$$

IJECE Vol. 5, No. 5, October 2015 : $1134-1142$ 
where $\mathrm{D}$ is diameter of the rain drop.

Adopting the Marshall-Palmer Z-R relation, the reflectivity factor can be rewritten as [28]:

$$
Z=a R^{b}\left(\mathrm{~mm}^{6} \mathrm{~m}^{-3}\right)
$$

where the values for a and $\mathrm{b}$ are 200 and 1.6 respectively.

Therefore, rain rate:

$$
R=\left[\frac{10^{(d B Z / 10)}}{200}\right]^{1 / 1.6}
$$

This paper investigates seasonal and diurnal variations of rain heights in Johor, Malaysia from ground-based meteorological and satellite (TRMM) precipitation radar data. This approach takes advantage of the inherent accuracy of the ground-based S-band meteorological radar on one hand and the large footprint presented by the space-borne Ku-band precipitation radar (PR), on the other hand. Furthermore, both ground-based and TRMM PR 2A23 data were classified into day and night in order to investigate diurnal dependence of rain height.

Section 2 presents the method employed to extract the measurement data from both ground-based and space-borne precipitation radars. Results obtained from section 2 and its analysis thereof is espoused in section 3. Finally, section 4 concludes the findings of this work.

\section{METHODOLOGY}

\subsection{Ground-Based Radar Data}

For the ground-based radar, data sourced from the Malaysian Meteorological Department's Kluang radar station $\left(2.02^{\circ} \mathrm{N}, 103.38^{\circ} \mathrm{E}\right)$ was utilized. UTM $\left(1.56^{\circ} \mathrm{N}, 103.64^{\circ} \mathrm{E}\right)$ is $62 \mathrm{~km}$ from Kluang radar station with an estimated azimuthal angle of $169^{\circ}$ [29]. One year measurement data taken between November 1 , 2006 and November, 302007 was used in this analysis. The classification of the rain events were evaluated by radar operators at the Malaysian Meteorological Department with the minimum amount of the rain rate that the radar can detect using the widely accepted the Marshall-Palmer empirical relationship of the radar reflectivity factor as given in Equation (3).

The Kluang radar is a three-dimensional RAPIC system that utilizes two scan modes. These are the plan position indicator (PPI) and rain height indicator (RHI). The minimum and maximum search windows were set to 1 and $15 \mathrm{~km}$ respectively; hence the volumetric elevations angles used in this work are $1.1^{\circ}, 1.9^{\circ}$, $3.3^{\circ}, 5.8^{\circ}, 7.7^{\circ}, 10.3^{\circ}, 13.6^{\circ}$, and $18.1^{\circ}$. The GR (ground-based radar) data is filtered out from the other stations contained in the raw data using some program codes in MATLAB. Thereafter, the eight volumetric elevation angles used were extracted from the filtered Kluang data, also using MATLAB program coding. However, only data scanned at a higher resolution of 500 meters were extracted from the data. Since the raw data is encoded in ASCII, the extracted data is decoded and finally the vertical reflectivity profile (VRP) is plotted from the eight selected elevation angles recorded through the $169^{\circ} \mathrm{RHI}$ azimuthal scan range. The VRP was subsequently used to obtain various rain height parameters, such as rain and $0^{\circ} \mathrm{C}$ isotherm heights and bright-band thickness.

To ensure reliable radar rain information, non-rain echoes are eliminated since they possess inherently larger spatial variability when compared to rainy events. Hence, 48,324 rain events out of a total of 52,560 annual scans were utilized; translating to $91.9 \%$ yearly rain availability [29].

\subsection{TRMM PR data}

The TRMM PR 3A25 data product computes the monthly statistics of the PR measurements at both a low horizontal resolution of $5^{\circ} \times 5^{\circ}$ latitude-longitude and a high horizontal resolution of $0.5^{\circ} \times 0.5^{\circ}$ latitude-longitude. The low resolution grids are in the Planetary Grid 1 structure and include mean and standard deviation of the rain rate, reflectivity, path-integrated attenuation (PIA), storm height, Xi, BB height and the NUBF (Non-Uniform Beam Filling) correction, rain fractions and histograms of the storm height, etc. The high resolution grids in the Planetary Grid 2 structure are for computing mean rain rate, standard deviation and rain fractions [30]. The low resolution grids were used in this work because the Grid 2 structure is replete with large number of missing data; thus impinging on data reliability and integrity.

Data spanning two years (May 2011 to May 2013) sourced from [31] was utilized to complement the GR data. Twenty-two months (January 2011 to May 2013) 3A25 and seventeen months (January 2012 to May 2013) 2A23 radar data were used [29]. A portion of Johor area $\left(1.48^{\circ}, 103^{\circ}\right),\left(1.72^{\circ}, 104^{\circ}\right)$ was selected

Seasonal and diurnal variability of rain heights at an equatorial station (Abayomi Isiaka O. Yussuff) 
on the map and data downloaded from [31]. The downloaded data are in HDF format and are also compressed. A total of 1.865 GB of 3A25 Monthly TRMM was stored after extraction, while that of the daily TRMM 2A23 data amount to 7.16 GB of disk space after decompression. There are a total of 460 files in 2 folders for the 2A23 data, while that of the 3A25 comprise a total of 36 files. The selected 3A25 and 2A23 data contains 72,382 and 61,369 rain scans respectively [29].

\section{RESULTS AND DISCUSSIONS}

The TRMM rain height seasonal variations for North-East (NE), pre-NE, South-West (SW) and preSW monsoons for Johor, Malaysia are displayed in Figures 1 and 2; while that from the meteorological radar are given in Figures 3 and 4.

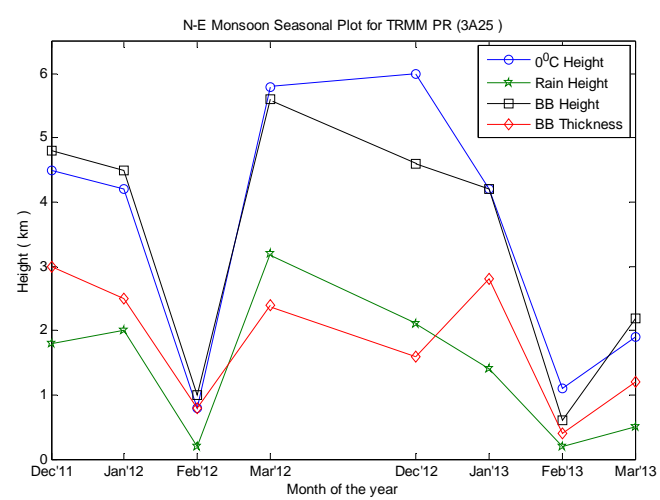

(a)

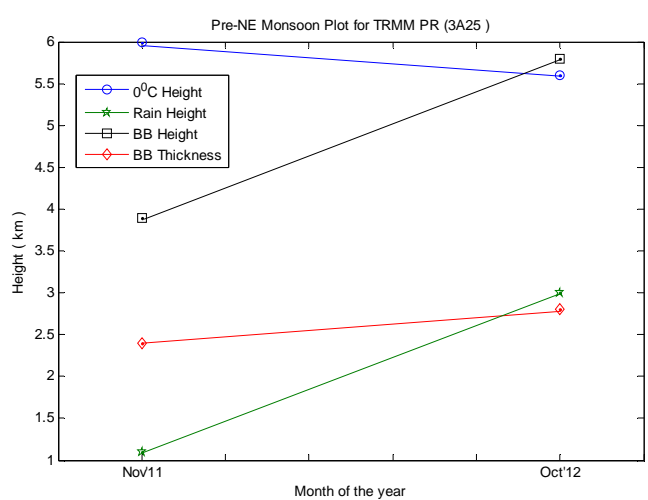

(b)

Figure 1. TRMM (a) North-East and (b) Pre-North-East Monsoon rain height variations for Johor, Malaysia for May 2011 to May 2013

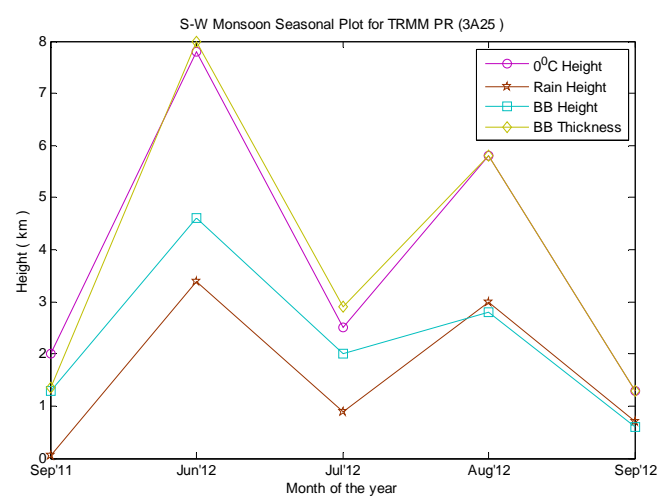

(a)

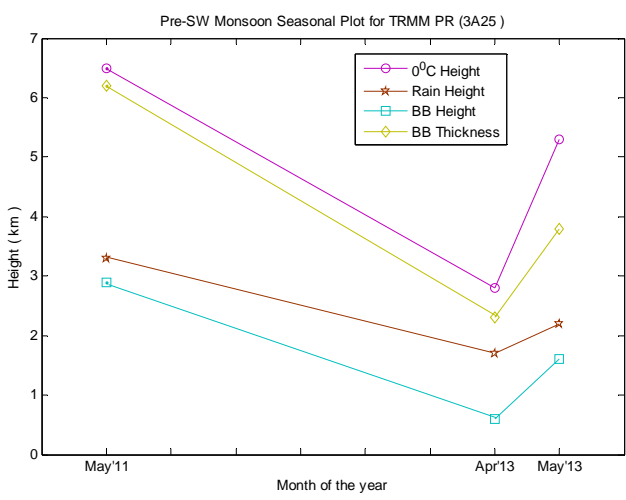

(b)

Figure 2. TRMM (a) South-West Monsoon rain height variations for 2011 and 2012 and (b) Pre-South-West Monsoon rain height variations for Johor, Malaysia for 2011 and 2013 


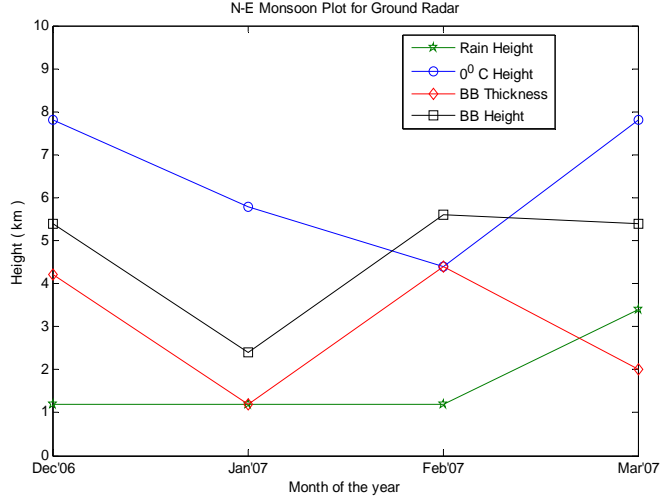

(a)

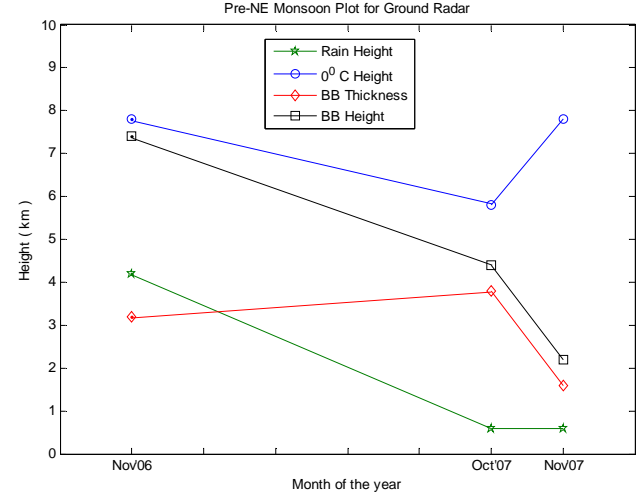

(b)

Figure 3. GR North-East and (b) Pre-North-East Monsoon rain height variations for Johor, Malaysia for November 2006 to November 2007

From Figures 1(a) and 2(a), $H_{0}$, BB thickness and $H_{R}$ are 3.44, 1.63 and $1.43 \mathrm{~km}$; and 3.88, 3.87 and $1.61 \mathrm{~km}$ for NE and SW monsoons respectively for TRMM. For TRMM pre-NE and pre-SW monsoons (see Figures 1(b) and 2(b)), $H_{0}$, BB thickness and $H_{R}$ are $0.52,029$ and $0.19 \mathrm{~km}$; and 4.87, 4.10 and $2.40 \mathrm{~km}$ respectively.

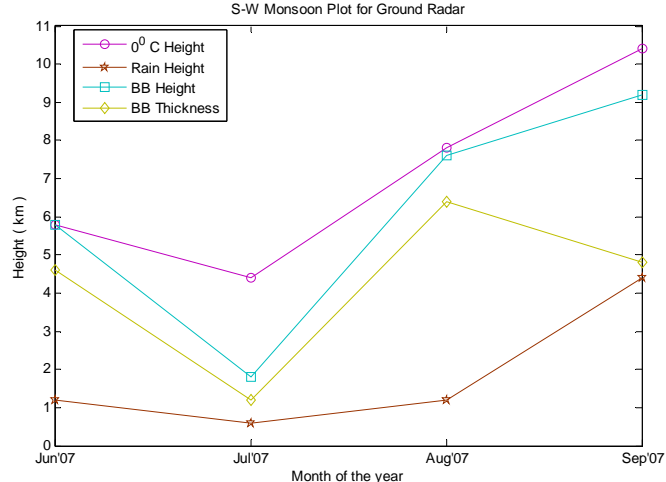

(a)

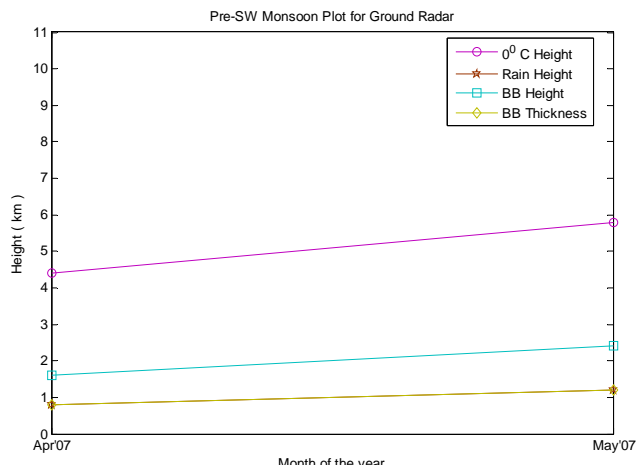

(b)

Figure 4. GR South-West and (b) Pre-South-West Monsoon rain height variations for Johor, Malaysia for 2007

Similarly, for GR (Figures 3(a) and 4(a)), $H_{0}$, BB thickness and $H_{R}$ are 6.45, 2.90 and $1.75 \mathrm{~km}$; and $7.10,4.25$ and $1.85 \mathrm{~km}$ for NE and SW monsoons respectively, while pre-NE and pre-SW monsoons rain height parameters (Figures 3(b) and 4(b)) are 7.13, 2.87 and $1.80 \mathrm{~km}$; and 5.10, 1.00 and $1.00 \mathrm{~km}$ respectively for $H_{0}$, BB thickness and $H_{R}$.

The month-to-month variation plots for both TRMM and GR data are shown in Figures 5 and 6 respectively. From Figure 9, it is observed that, the mean $H_{0}$, BB thickness and $H_{R}$ are at their peak in the months of May, June, and October. However, these parameters are lowest in the months of February, July and September. 


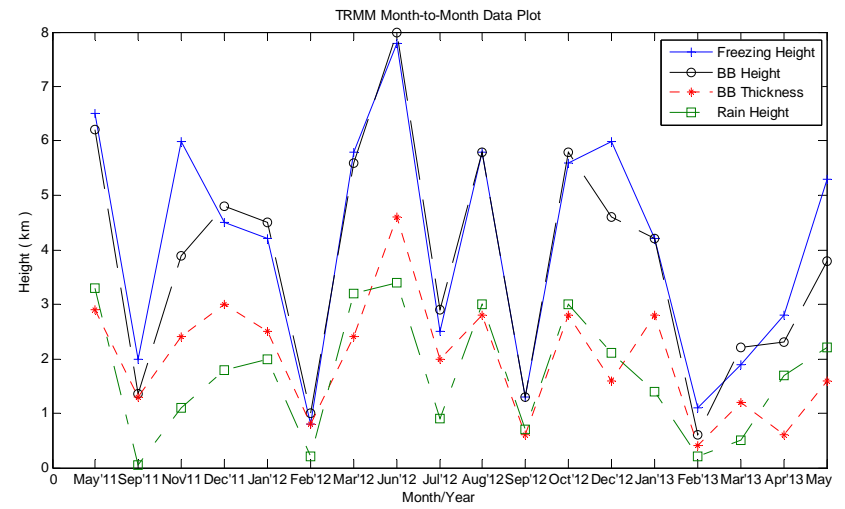

Figure 5. TRMM Month-to-month rain height variations for May 2011 to May 2013

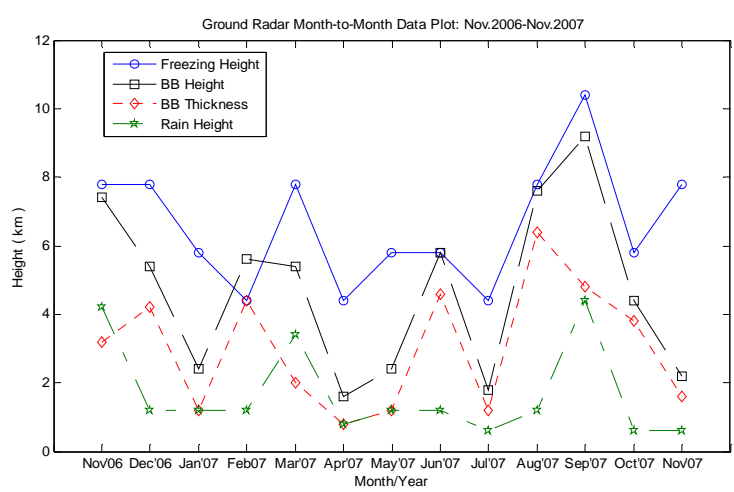

Figure 6. GR Month-to-month rain height variations for November 2006 to November 2007

Furthermore, diurnal measurements obtained from both satellite and meteorological radars diurnal bright-band parameters for the month of May, 2013 are studied. Both GR and TRMM PR 2A23 data were classified into day (06:00 to 18:00) and night (18:01 to 5:59) local time. Diurnal variation plots for TRMM are displayed in Figures 7(a) and (b); while that for GR are given in Figures 8(a) and (b). From Figures 7and 8, $H_{0}$, BB thickness and $H_{R}$ for day-time and night-time are 4.30, 0.024 and $3.55 \mathrm{~km}$; and 4.26, 0.015 and $3.68 \mathrm{~km}$ respectively for TRMM. Similarly, $H_{0}$, BB thickness and $H_{R}$ are 6.78, 6.20 and $1.95 \mathrm{~km}$; and 7.05, 3.13 and $2.03 \mathrm{~km}$ for day-time and night-time respectively for GR.

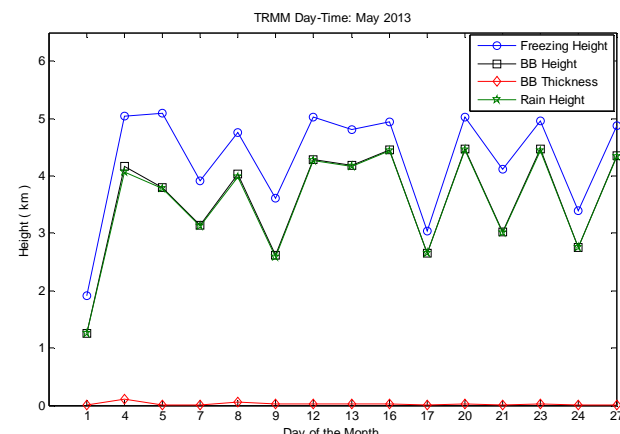

(a)

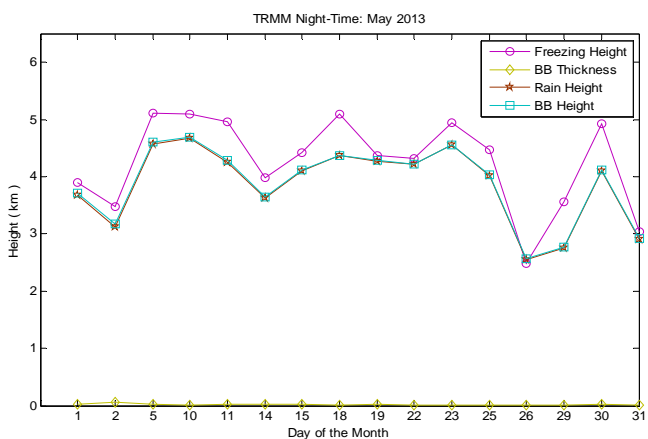

(b)

Figure 7. TRMM PR 2A23 (a) Day-time and (b) Night-time rain height variations for May 2013 for Johor, Malaysia 


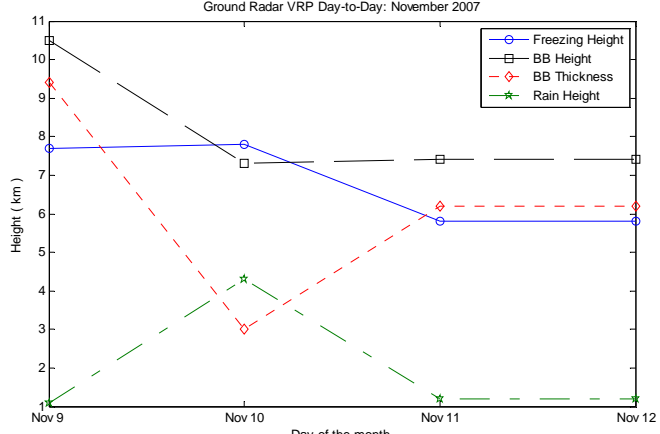

(a)

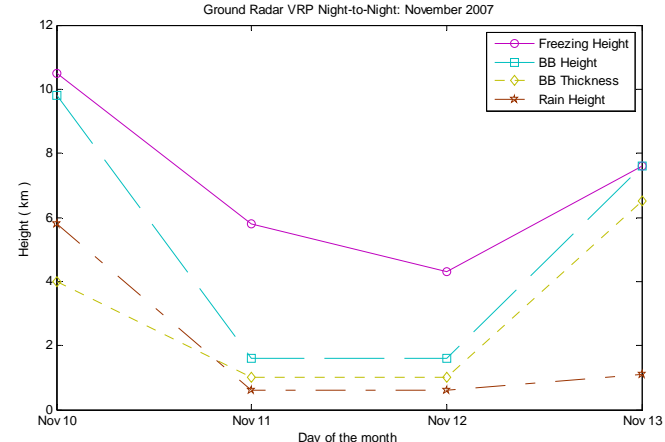

(b)

Figure 8. GR (a) Day-time and (b) Night-time rain height variations in May 2013 for Johor, Malaysia

These observations suggest diurnal dependence of these rain height parameters. The mean values showed that the BB is thicker in the day while the freezing and rain heights are higher in the night-time. Furthermore, the rain heights are higher during the rainy seasons (i.e. NE and SWmonsoons), but lowest at the end of the monsoons. It is also slightly higher during the NE monsoon than during the SW monsoon, suggesting seasonal dependence.

Table 1. Comparison of measured rain height parameters with results from other tropical stations

\begin{tabular}{lcccc}
\hline \multicolumn{1}{c}{ Source } & $\begin{array}{c}\text { Freezing Height }\left(\mathrm{H}_{0}\right) \\
(\mathrm{km})\end{array}$ & $\begin{array}{c}\text { BB Height } \\
(\mathrm{km})\end{array}$ & $\begin{array}{c}\text { BB Thickness } \\
(\mathrm{km})\end{array}$ & $\begin{array}{c}\text { Rain Height } \\
\left(\mathrm{H}_{\mathrm{R}}\right)(\mathrm{km})\end{array}$ \\
\hline ITU-R P. 839-3 [17] & 4.50 & $\mathrm{NA}$ & $\mathrm{NA}$ & 4.86 \\
TRMM-PR, UAE [24] & 5.00 & 4.4 & 1.25 & 3.75 \\
TRMM-PR, Singapore [32] & 4.14 & 4.2 & $<1.0$ & 4.5 \\
Pontes et al., Brazil [33] & 3.35 & $\mathrm{NA}$ & $\mathrm{NA}$ & 3.71 \\
Ojo et al., Nigeria [34] & 4.69 & $\mathrm{NA}$ & $\mathrm{NA}$ & 5.05 \\
Khamis et al., Malaysia [35] & 2.95 & 3.96 & 1.83 & 1.98 \\
Current work, GR, Malaysia [29] & 6.60 & 4.71 & 3.03 & 1.68 \\
Current work, TRMM-PR 3A25, Malaysia [29] & 4.12 & 3.83 & 2.02 & 1.71 \\
Current work, TRMM-PR 2A23, Malaysia [29] & 4.28 & 3.73 & & 0.02 \\
\hline
\end{tabular}

NA: Not available.

Table 1 compares the results of measurements obtained in this work with those obtained from Malaysia and other tropical stations; and also with that of the ITU-Rec. P. 839-3 [17]. The variations were found to depend on the latitudeof the station [32] and time the data was taken [36], [37]. Additionally, the disagreement between results from [35] and this work may be due to higher resolution of 500 m employed this work, against 1000 metres for [35]. Furthermore, data utilized by [35] span only six months (January to June 1998). ITU-R. P.839-3 [17] did not directly take into account seasonal and diurnal variations of stations in its estimation for rain height. It assumed constant rain heights (see Equation (1)), which is partly responsible for the variations observed in results from [34].Although [17] also recommended that local data should be used if available (as utilized in this work). The results presented by [24] are global in nature and the estimations thereof are for both over land and oceans, while the results from this work is specifically for Johor, Malaysia and the data utilized are over land. Differences in the results from Thurai et al.[32] and TRMM 3A25 from this work may be due to the adoption of ITU-R. P. 839-3 model by [32]. Finally, results from [33] were based on effective rain heights and adoption of ITU-R. P.839-3 model; hence the discrepancy.

\section{CONCLUSIONS}

Good understanding of rain height characteristics presents valuable information about the microphysical processes involved in rain precipitation, and thusproviding a better approach in the estimation of rain attenuation prediction and modelling. Additionally, diurnal and seasonal changes, as observed could be used to predict the time of the day or period of the year serious rain attenuation is likely to be 
experienced.Higher seasonal variability was observed during south-west and pre-southwest monsoons. The only exception to this is pre-southwest monsoon for ground-based radar (being lower than that of the prenortheast monsoon). Radar measurement data is known to present huge rainfall precipitation information; with the ability to capture real time spatio-temporal variations of precipitations. The bright-band is thicker in the day. The rain heights are higher in the night than in the day time. The rain heights are higher during the rainy seasons, but lowest at the end of the monsoons. It is also slightly higher during the NE monsoon than during the SW monsoon, suggesting seasonal dependence.ITU-R. P.839-3model is not suitable for use in most tropical stations because it assumed constant rain heights anddid nottake into account seasonal or diurnal variations of stations in its estimations of rain heights.

\section{ACKNOWLEDGEMENTS}

The authors acknowledge JAXA Earth Observation Research Center and Malaysian Meteorological Departmentfor making available the TRMM and ground-based precipitation radar data respectively.

\section{REFERENCES}

[1] A.I. Yussuff and N.H. Khamis, "Rain Attenuation Modelling and Mitigation in the Tropics: Brief Review", International Journal of Electrical and Computer Engineering, vol. 2, no. 6, pp. 748-757, 2012.

[2] ITU-R. P. 618-11. "Propagation Data and Prediction Methods Required for the Design of Earth-Space Telecommunications Systems”, Recommendation ITU-R P Series, 2013.

[3] A.I.O. Yussuff and N.H.H. Khamis, "Determination of Melting Layer Boundaries and Attenuation Evaluation in Equatorial Malaysia at Ku-Band”, Bulletin of Electrical Engineering and Informatics, vol. 3, no. 4, pp. 293-302, 2014.

[4] A.I.O. Yussuff and N.H.H. Khamis, "Bright-Band Characterization in a Tropical Station from Ground-based Radar Data”, International Journal of Earth Sciences and Engineering, vol. 7, no. 3, pp. 882-889, 2014.

[5] K.K. Reddy and T. Kozu, "Measurements of raindrop size distribution over Gadanki during south-west and north-east monsoon”, Indian Journal of Radio \& Space Physics, vol. 32, pp. 286-295, 2003.

[6] Hong Yin Lamet al., "Assessment of Seasonal Asia Monsoon Rain Impact on the Earth-Space Propagation in Equatorial Kuala Lumpur”, Paper presented at the Proceedings of ISAP2012, Nagoya, Japan, 2012.

[7] T. Kozuet al., "Seasonal and diurnal variation of raindrop size distribution in Asian monsoon region", Journal of Applied Meteor. Soc. Japan, 84A, pp. 195-209, 2006.

[8] Y.N. Takayabu, "Spectral representation of rain profiles and diurnal variations observed with TRMM PR over the equatorial area”, Geophys.Res. Lett., 29, 1584, 2002. doi:10.1029/ 2001GL014113.

[9] S. Mori, et al.,"Diurnal land-sea rainfall peak migration over Sumatra Island, Indonesian maritime continent observed by TRMM satellite and intensive rawinsonde soundings”, Monthly Weather Rev., 132, pp. 2021-2039, 2004.

[10] S. Chiu Long, et al., "Rain estimation from satellites: Effect of finite field of view", Journal of Geophysical Research: Atmospheres, (1984-2012), vol. 95, no. D3, pp. 2177-2185, 1990.

[11] A.R. Sharul Kamal, et al., "Rain attenuation study over terrestrial and earth-satellite links in Malaysia”, pp. 1-4, 2014.

[12] D.B. Shin, and Gerald R. North, "Errors incurred in sampling a cyclostationary field”, Journal of Atmospheric and Oceanic Technology, vol. 17, no. 5, pp. 656-664, 2000.

[13] E.N. Anagnostou and C.A. Morales, "The use of TRMM Precipitation Radar Observations in Determining Ground radar Calibration Biases”, Journal of Atmospheric and Oceanic Technology, vol.18, Pg. 618, 2001.

[14] S. Ziad Haddad and Kyung-Won Park, "Vertical Profiling of Tropical Precipitation using Passive Microwave Observations and its Implications regarding the crash of AF447”, Journal of Geophysical Research, 115(D12), D12129, 2010.

[15] J. Simpson, et al., "On the Tropical Rain Measuring Mission (TRMM)”, Meteorological Atmospheric Physics, vol. 60, pp. 19-36, 1996.

[16] M. Thurai, et al, "Rain Height Variability in the Tropics and Implications for Rain Scatter Interference", IEEE Transaction on Antennas amd Propagation, pp. 997-1001, 2005.

[17] ITU-R. P.839-3, Rain height model for prediction methods, Recommendation ITU-R P Series, 2001.

[18] G.O. Ajayi and P.A. Odunewu, "Some Characteristics of the Rain Height in a Tropical Environment", IEEE Transactions on Antennas and Propagation, pp. 80-82, 1989.

[19] O. Adetan, et al. ,"Raindrop size distribution and rainfall attenuation modeling in equatorial and subtropical Africa: the critical diameters”, Annals of telecommunications-annales des télécommunications, pp. 1-13, 2014.

[20] A. Adhikari, et al.,"Rain-induced scintillations and attenuation of Ku-band satellite signals at a tropical location”, Geoscience and Remote Sensing Letters, IEEE, vol. 9, no. 4, pp. 700-704, 2012.

[21] B.K. Mandal, et al., "Attenuation of Signal at a Tropical Location with Radiosonde Data Due to Cloud", International Journal of Smart Home, vol.8, no. 1, pp. 15-22, 2014.

[22] S.K.A. Rahim, et al., "Microwave signal attenuation over terrestrial link at $26 \mathrm{GHz}$ in Malaysia”, Wireless Personal Communications, vol. 67, no. 3, pp. 647-664, 2012. 
[23] E.S.M Thurai and K. Okamoto, "Rain Height Variability in the Tropics and Implications for Rain Scatter Interference”, IEEE Transactions on Antennas and Propagation, pp. 997-1001, 2005.

[24] Khalid Mubara, et al., "Global Mapping of Height of Bright Band". Paper presented at the Signal Processing and Its Applications, ISSPA 2007. 9th International Symposium. IEEE, pp. 1-4, 2007.

[25] Merhala Thurai, et al., "Freezing height distribution in the tropics", International Journal of Satellite Communications and Networking, vol. 21, pp. 533-545, 2003.

[26] N.H.H. Khamis, et al., "Month-to-Month variability of the Melting Layer Boundaries", Asia pacific Conference on Applied Electromagnetics Proceedings, Malaysia, 2007.

[27] J.S. Mandeep, "Rain height statistics for satellite communication in Malaysia", Journal of Atmospheric and SolarTerrestrial Physics, vol.70, pp.1617-1620, 2008.

[28] J.S. Marshall and W.M.K. Palmer, "The distribution of raindrops with size”, Journal of meteorology, vol. 5, no. 4, pp. 165-166, 1948.

[29] A.I.O.Yussuff, "Characterization of bright-band in a tropical station for satellite communications”, Ph.D. Thesis. Dept. of Communications Engineering, Universiti Teknologi Malaysia, 2014.

[30] NASA, “Precipitation Processing System TRMM File Specification for TRMM Products”, version 7.001, pg. 205, 2011.http://disc.sci.gsfc.nasa.gov/gesNews/version_7_tmpa-rt_release

[31] JAXA Earth Observation Research Center. JAXA Global Rainfall Watch. Retrieved Dec. 18, 2013, from http://sharaku.eorc.jaxa.jp/GSMaP/index.htm

[32] M. Thurai, et al., "Rain height variability in the Tropics", IEE Proc.-Microwave Antennas Propagation, vol. 152, no. 1, pp. 17-23, 2005.

[33] M.S. Pontes, et al., "Statistical behaviour of the effective rain height in the tropics", Paper presented at 9th International Conference on Antennas and Propagation, pp. 119-122, 1995.

[34] J.S. Ojo, et al., " $0^{\circ} \mathrm{C}$ isotherm height distribution for Earth-space communication satellite links in Nigeria", Indian Journal of Radio \& Space Physics, vol. 43, June 2014, pp. 225-234, 2014.

[35] N.H.H. Khamis, et al., "Determination of the Melting Layer from Meteorological Radar Data in Malaysia", IEEE Transactions on Antennas and Propagation, pp. 1467-1470, 2007.

[36] B.A. Fabry Bellonand I.I. Zawadzki, "Long Term Observations of the Melting Layer Using Vertically Pointing Radars MW-101", Cooperative Centre for Research in Mesometeorology (CCRM), Report, Canada: McGill University, vol. 65, pp. 1-65, 1994.

[37] S.W. Nesbitt and E.J. Zipser, "The Diurnal Cycle of Rainfall and Convective Intensity according to Three Years of TRMM Measurements”, Journal of Climate, vol.16, pp. 1456-1475, 2003.

\section{BIOGRAPHIES OF AUTHORS}
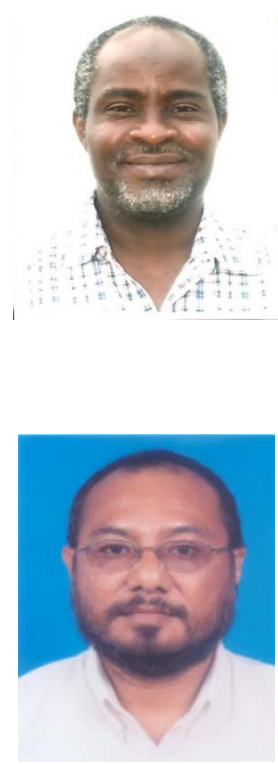

Abayomi Isiaka O. Yussuff obtained his bachelor and master's degrees in Electronic and Computer Engineering from Lagos State University, Nigeria in 1994 and 2003; and a PhD in Electrical Engineering from Universiti Teknologi Malaysia (UTM), Skudai, Malaysia in 2014. $\mathrm{He}$ is currently a researcher and lecturer in the Department of Electronic and Computer Engineering, Lagos State University, Epe campus, Nigeria. His research area of interests includes radio propagation and rain attenuation studies in the tropics, computer security, electronic instrumentation and measurements. He has published a few papers in international journals related to satellite rain attenuation issues in the tropical regions. He is a member of Nigeria Society of Engineers (NSE) and IEEE; and licensed by the Council for Regulation of Engineering in Nigeria (COREN).

Nor Hisham Haji Khamis is a senior lecturer in the Department Communications Engineering, Faculty of Electrical Engineering Department, Universiti Teknologi Malaysia, Skudai, Johor. He received his B.Sc.E.E. from the University of Evansville, Indiana, USA in 1988, M.E.Sc.E.E. from the University of New South Wales, Australia in 1992, and PhD from UTM in 2005. He joined UTM in 1989 and currently is the Head of Radar Laboratory. He is also the subject coordinator for the Microwave Engineering, RF Microwave Circuit Design, and Radar courses at the faculty. He also leads the Sonar and Marine Instrumentation Research Group (STAR). His research interest includes antenna design especially microstrip antenna, microwave components, wireless transmission, and propagation studies. Dr. Khamis is a member of Eta Kappa $\mathrm{Nu}$ (Electrical Engineering Honor Society, USA) and IEEE. 